\title{
Infrared absorption spectra, radiative efficiencies, and global warming potentials of perfluorocarbons: Comparison between experiment and theory
}

Article

Published Version

Bravo, I., Aranda, A., Hurley, M. D., Marston, G., Nutt, D. R., Shine, K. P., Smith, K. and Wallington, T. J. (2010) Infrared absorption spectra, radiative efficiencies, and global warming potentials of perfluorocarbons: Comparison between experiment and theory. Journal of Geophysical Research, 115. D24317. ISSN 0148-0227 doi:

https://doi.org/10.1029/2010JD014771 Available at https://centaur.reading.ac.uk/18161/

It is advisable to refer to the publisher's version if you intend to cite from the work. See Guidance on citing.

To link to this article DOI: http://dx.doi.org/10.1029/2010JD014771

Publisher: American Geophysical Union

All outputs in CentAUR are protected by Intellectual Property Rights law, including copyright law. Copyright and IPR is retained by the creators or other copyright holders. Terms and conditions for use of this material are defined in the End User Agreement. 


\section{www.reading.ac.uk/centaur}

\section{CentAUR}

Central Archive at the University of Reading

Reading's research outputs online 


\title{
Infrared absorption spectra, radiative efficiencies, and global warming potentials of perfluorocarbons: Comparison between experiment and theory
}

\author{
Iván Bravo, ${ }^{1}$ Alfonso Aranda, ${ }^{1}$ Michael D. Hurley, ${ }^{2}$ George Marston, ${ }^{3}$ David R. Nutt, ${ }^{3}$ \\ Keith P. Shine, ${ }^{4}$ Kevin Smith, ${ }^{5}$ and Timothy J. Wallington ${ }^{2}$
}

Received 17 July 2010; revised 21 September 2010; accepted 29 September 2010; published 31 December 2010.

[1] Experimentally and theoretically determined infrared spectra are reported for a series of straight-chain perfluorocarbons: $\mathrm{C}_{2} \mathrm{~F}_{6}, \mathrm{C}_{3} \mathrm{~F}_{8}, \mathrm{C}_{4} \mathrm{~F}_{10}, \mathrm{C}_{5} \mathrm{~F}_{12}, \mathrm{C}_{6} \mathrm{~F}_{14}$, and $\mathrm{C}_{8} \mathrm{~F}_{18}$. Theoretical spectra were determined using both density functional (DFT) and ab initio methods. Radiative efficiencies (REs) were determined using the method of Pinnock et al. (1995) and combined with atmospheric lifetimes from the literature to determine global warming potentials (GWPs). Theoretically determined absorption cross sections were within $10 \%$ of experimentally determined values. Despite being much less computationally expensive, DFT calculations were generally found to perform better than ab initio methods. There is a strong wavenumber dependence of radiative forcing in the region of the fundamental C-F vibration, and small differences in wavelength between band positions determined by theory and experiment have a significant impact on the REs. We apply an empirical correction to the theoretical spectra and then test this correction on a number of branched chain and cyclic perfluoroalkanes. We then compute absorption cross sections, REs, and GWPs for an additional set of perfluoroalkenes.

Citation: Bravo, I., A. Aranda, M. D. Hurley, G. Marston, D. R. Nutt, K. P. Shine, K. Smith, and T. J. Wallington (2010), Infrared absorption spectra, radiative efficiencies, and global warming potentials of perfluorocarbons: Comparison between experiment and theory, J. Geophys. Res., 115, D24317, doi:10.1029/2010JD014771.

\section{Introduction}

[2] Perfluorocarbons (PFCs) are regulated as part of the Kyoto Protocol. There is significant interest in determining the contribution to radiative forcing of climate change of emissions of PFCs and related molecules such as hydrofluorocarbons (HFCs) and hydrochlorofluorocarbons (HCFCs). Laboratory measurements of the infrared (IR) absorption spectra of PFCs have been reported by several research groups [see, e.g., Roehl et al., 1995; Sihra et al., 2001; Clerbaux et al., 1993; Hurley et al., 2005; Bera et al., 2010]. From these measurements, the radiative efficiency (RE) of the species is determined which, together with the atmospheric lifetime, allows an assessment of its global warming potential (GWP). There are a large number of PFCs which could potentially be emitted into the atmosphere and it is not practical to measure the IR spectra of all of them. Consequently, the potential of theoretical methods to

\footnotetext{
${ }^{1}$ Physical Chemistry Department, University of Castilla-La Mancha, Ciudad Real, Spain.

${ }^{2}$ Systems Analytics and Environmental Sciences Department, Ford Motor Company, Dearborn, Michigan, USA.

${ }^{3}$ Department of Chemistry, University of Reading, Reading, UK.

${ }^{4}$ Department of Meteorology, University of Reading, Reading, UK.

${ }^{5}$ Space Science and Technology Department, Rutherford Appleton Laboratory, Didcot, UK.

Copyright 2010 by the American Geophysical Union. 0148-0227/10/2010JD014771
}

predict IR spectra has also been explored. Previous research [e.g., Papasavva et al., 1995, 1997; Blowers et al., 2007; Young et al., 2008; Bera et al., 2010] has indicated that it is possible to calculate infrared spectra using ab initio methods with useful accuracy, and that radiative transfer models can then be applied to these spectra to determine radiative efficiencies and hence GWPs.

[3] The present work uses density functional theory and ab initio methods to determine the absorption cross section and compares these with those determined using experimental IR spectra. Our approach has been to start with the most basic type of fluorinated compounds, namely the straight-chain perfluoroalkanes, as the C-F bond plays a major role in the absorption spectrum. The most comprehensive experimental study of the IR spectra of these compounds is that of Roehl et al. [1995], who examined the cross sections, REs and GWPs of the C1-C6 series of perfluoroalkanes. However, their paper provides only limited information on the spectra (tabulated integrated cross sections over quite wide spectral intervals) of these compounds, and so it was not possible for us to make a detailed comparison of our theoretical spectra, REs and GWPs with their experimental results. We have therefore measured the infrared spectra of a series of straight-chain perfluoroalkanes $(\mathrm{C} 2-\mathrm{C} 6$ and $\mathrm{C} 8$, combined with $\mathrm{C} 1$ and $\mathrm{C} 10$ from previous measurements in our laboratories), and used these measurements as the basis for comparison with our theo- 
retical results. We will show that to achieve sufficient accuracy in the calculation of the radiative efficiency using the theoretical spectra, it is necessary to make an empirical correction to the wavenumber of the band centers; to test the applicability of this correction, we apply it to a number of cyclic and branched perfluoroalkanes and then report results for a number of perfluoroalkenes.

\section{Materials and Methods}

\subsection{Experimental Infrared Spectra Measurements}

[4] Infrared spectra of $\mathrm{C}_{2} \mathrm{~F}_{6}, \mathrm{C}_{3} \mathrm{~F}_{8}, \mathrm{n}-\mathrm{C}_{4} \mathrm{~F}_{10}, \mathrm{n}-\mathrm{C}_{5} \mathrm{~F}_{12}, \mathrm{n}-$ $\mathrm{C}_{6} \mathrm{~F}_{14}$ and $\mathrm{n}-\mathrm{C}_{8} \mathrm{~F}_{18}$ were measured at the Rutherford Appleton Laboratory (RAL) Molecular Spectroscopy Facility (MSF). We are not aware of previous measurements of $\mathrm{C}_{8} \mathrm{~F}_{18}$ in the literature. Measurements were obtained at $297 \mathrm{~K}$ using a Bruker IFS $125 \mathrm{HR}$ spectrometer in the range $600-1800 \mathrm{~cm}^{-1}$ with a $5 \mathrm{~cm}$ path length stainless steel cell fitted with $\mathrm{KBr}$ windows. The spectrometer was operated at a spectral resolution of $0.01 \mathrm{~cm}^{-1}$ with interferograms being obtained from 100 coadded scans. Spectra were recorded either of the pure vapor or in the presence of 60-506 $\mathrm{hPa}$ of $\mathrm{N}_{2}$ diluent. Wide and narrow band MCT detectors, with long wave cutoffs of 500 and $800 \mathrm{~cm}^{-1}$, were used to measure spectra in the $700-1400 \mathrm{~cm}^{-1}$ region using a $\mathrm{KBr}$ beam splitter and globar infrared source.

[5] In all experiments, pure compounds were transferred to a small glass vial via a welded stainless steel gas line and degassed by freeze/pump/thaw cycles before use. For the measurements of the pure vapor, the desired quantity of material was allowed into the cell, and the pressure monitored throughout the recording of the spectrum.

[6] The mixtures in nitrogen were made up in $1000 \mathrm{~cm}^{3}$ capacity glass bulbs. The compound of interest was allowed into the bulb to a pressure of about $0.33-1.33 \mathrm{hPa}$ and then made up with nitrogen $(\sim 1000 \mathrm{hPa})$. Bulbs of the compound of interest in $\mathrm{N}_{2}$ were mixed in this way and allowed to stand overnight to allow good mixing of the two gases.

[7] To ensure that saturation was not a problem in the measurements, the peak absorbance was plotted as a function of pressure for each compound. Absorption cross sections were derived from the slopes of the linear portions of the plots. The spectra were then normalized to this value for the cross section. Absorption cross sections at temperature $T(\mathrm{~K})$ and wavenumber $\bar{v}\left(\mathrm{~cm}^{-1}\right)$ at the experimental resolution were determined through the relationship

$$
\sigma(\bar{v}, T)=\ln \left(I_{0} / I\right) / c l,
$$

where $\sigma(\bar{v}, T)$ is the absorption cross section in $\mathrm{cm}^{2}$ molecule $^{-1}, I_{0}$ is the intensity of radiation reaching the detector when the cell is evacuated, $I$ is the intensity of radiation reaching the detector when the cell contains the sample, $c$ is the concentration of sample (molecule $\mathrm{cm}^{-3}$ ) and $l$ is the path length $(\mathrm{cm})$. Integrated absorption cross sections $S(T)$ in $\mathrm{cm}^{2}$ molecule $\mathrm{cm}^{-1}$ between wavenumbers $\bar{v}_{1}$ and $\bar{v}_{2}$ were determined according to the expression

$$
S(T)=\int_{\bar{v}_{1}}^{\bar{v}_{2}} \sigma(\bar{v}, T) d \bar{v} .
$$

[8] Absorption cross sections were also measured at room temperature between 650 and $3800 \mathrm{~cm}^{-1}$ at the Ford Motor
Company, Michigan (referred to as Ford, hereafter), using the techniques described by Sihra et al. [2001], Hurley et al. [2005] and references therein. These included $n-C_{4} F_{10}$ and $\mathrm{n}-\mathrm{C}_{5} \mathrm{~F}_{12}$, allowing direct comparison with the MSF measurements (although our previous work on $\mathrm{CF}_{4}$ had shown that measurements in the two laboratories were indistinguishable within experimental uncertainties [Hurley et al., 2005]). In addition, we report measurements of $\mathrm{c}-\mathrm{C}_{4} \mathrm{~F}_{8}$, i- $\mathrm{C}_{4} \mathrm{~F}_{10}$, hexafluorocyclobutene $\left(\mathrm{C}_{4} \mathrm{~F}_{6}\right)$, hexafluoro-1-3butadiene (also $\mathrm{C}_{4} \mathrm{~F}_{6}$ ) and $\mathrm{c}-\mathrm{C}_{5} \mathrm{~F}_{8}$. For the latter three molecules, we are unaware of previous measurements in the literature.

[9] Previously reported measurements of other straightchain PFCs in our laboratories are also used in the analysis here [Sihra et al., 2001; Hurley et al., 2005].

\subsection{Reagents}

[10] The purities of the gases used at MSF were as follows: $\mathrm{C}_{2} \mathrm{~F}_{6}$ (Fluorochem Ltd., 99\%), $\mathrm{C}_{3} \mathrm{~F}_{8}$ (F2 Chemicals, 99.5\%); $\mathrm{n}-\mathrm{C}_{4} \mathrm{~F}_{10}$ (F2 Chemicals, 99\%); n- $\mathrm{C}_{5} \mathrm{~F}_{12}$ (F2 Chemicals, 95\%); $n-\mathrm{C}_{6} \mathrm{~F}_{14}$ (Sigma Aldrich, 99\%) and $\mathrm{n}-\mathrm{C}_{8} \mathrm{~F}_{18}$ (Sigma Aldrich, 98\%). Gases used at Ford were obtained from commercial sources at the following stated purities: $n-\mathrm{C}_{4} \mathrm{~F}_{10}(>99 \%), n-\mathrm{C}_{5} \mathrm{~F}_{12}(>99 \%), n-\mathrm{C}_{6} \mathrm{~F}_{12}$ (>99\%), perfluorocyclobutane $(>99 \%), i-\mathrm{C}_{4} \mathrm{~F}_{10}(>97 \%)$, hexafluorocyclobutene $(>99 \%)$, octafluorocyclopentene $(>99 \%)$, and hexafluoro-1,3-butadiene (>99\%). All samples were subjected to freeze-pump-thaw cycling before use.

\subsection{Computational Methods}

[11] The Gaussian03 software package [Frisch et al., 2004] was used to perform the theoretical calculations. The choice of level of theory and basis set are critical to obtain accurate results. The vibrational wavenumber calculation depends on the second derivative of the energy with respect to the atomic positions. Ab initio techniques (such as Hartree-Fock (HF), and second-order Moller-Plesset, MP2)) and density functional theory (DFT) methods (such as B3LYP) are combined with different basis sets to obtain infrared wavenumbers and intensities with different degrees of accuracy.

[12] Computational techniques have previously been used to predict infrared spectra to estimate values of radiative forcings [e.g., Papasavva et al., 1995], and it has been shown that the inclusion of electronic correlation is important to obtain accurate infrared intensities for small molecules [Yamaguchi et al., 1986; Miller et al., 1989; Amos et al., 1991; Bruns et al., 1997]. Papasavva et al. [1995] studied the infrared spectrum of $\mathrm{CF}_{3} \mathrm{CH}_{2} \mathrm{~F}$ using semiempirical AM1 and PM3 methods and HF and MP2 ab initio methods with a wide range of basis sets. Best results were obtained at the MP2/6-31G** level of theory. These authors also observed that deviations in the calculated wavenumbers were systematic and could be corrected using a scaling factor, and that the theoretical intensities were typically consistent with experiment.

[13] Halls and Schlegel [1998] found that DFT methods were also suitable for predicting infrared wavenumbers and intensities for a selection of small (two to six atoms) molecules, and even that these methods could be more accurate than MP2 and HF. They also studied the effect of the basis set, and found that larger basis sets containing 
polarized functions such as $6-31 G^{*}$ gave significantly better results than smaller basis sets. Other studies have demonstrated the importance of the use of polarized basis sets [Yamaguchi et al., 1986; Bruns et al., 1997]. Recently, Blowers et al. [2007, 2008a, 2008b] predicted infrared wavenumbers and intensities for a set of hydrofluoroethers using $\mathrm{B} 3 \mathrm{LYP} / 6-31 \mathrm{G}^{*}$. On the basis of previous studies, we have used both MP2 and B3LYP methods together with the 6-31G** basis set to study the PFC set: $\mathrm{CF}_{4}$, $\mathrm{C}_{2} \mathrm{~F}_{6}, \mathrm{C}_{3} \mathrm{~F}_{8}, \mathrm{n}-\mathrm{C}_{4} \mathrm{~F}_{10}, \mathrm{n}-\mathrm{C}_{5} \mathrm{~F}_{12}, \mathrm{n}-\mathrm{C}_{6} \mathrm{~F}_{14}$ and $\mathrm{n}-\mathrm{C}_{8} \mathrm{~F}_{18}$. We chose the $6-31 \mathrm{G}^{* *}$ basis set because of the importance of obtaining accurate band positions to determine REs for PFCs. Molecular structures were first optimized, followed by calculation of vibrational wavenumbers. No symmetry constraints were imposed. In all cases the absence of negative wavenumbers confirmed that we had obtained a minimum on the potential energy surface. When more than one minimum was found, the structure with the lowest Gibbs free energy was used for the calculation of radiative forcings. The impact of changes in conformation was tested for $n-C_{4} F_{10}$ by calculating spectra for different conformers. An overall spectrum for the molecule was determined by weighting the contributions from individual conformers according to the Boltzmann distribution. The difference in RE calculated from the spectrum of the most stable conformer and that including higher energy conformers was less than $1 \%$. This indicates that such effects are small for linear perfluoroalkanes.

\subsection{Calculating Radiative Forcing Efficiencies}

[14] Radiative forcing per unit concentration change or radiative efficiency (RE), is a fundamental parameter which measures the change in the Earth's radiation balance for a $1 \mathrm{ppbv}$ increase in concentration of the greenhouse gas. For any gas, this efficiency depends on the spectral variation of the absorption cross section, as the energy available to be absorbed in the atmosphere depends on this via both the Planck function and the absorption spectra of other species in the atmosphere [see e.g., Pinnock et al., 1995] Pinnock et al. [1995] used results from a relatively detailed radiative transfer model to develop a simple method that allows the determination of the RE of a gas from its experimentally measured infrared spectrum without the use of a complex radiative transfer model. In this approach, the RE is given by

$$
R E=\sum_{i=1}^{250} 10 \bar{\sigma}_{i}\left(\bar{v}_{i}\right) F_{i}\left(\bar{v}_{i}\right),
$$

where $\bar{\sigma}_{i}$ is the absorption cross section in $\mathrm{cm}^{2}$ molecule ${ }^{-1}$ averaged over a $10 \mathrm{~cm}^{-1}$ interval around the wavenumber $\bar{v}_{i}$, and $F_{i}\left(\bar{v}_{i}\right)$ is the instantaneous, cloudy sky, radiative forcing per unit cross section in $\mathrm{W} \mathrm{m}^{-2}\left(\mathrm{~cm}^{2} \text { molecule } \mathrm{cm}^{-1}\right)^{-1}$ for a 0 to $1 \mathrm{ppbv}$ increase in absorber. The values for $F_{i}\left(\bar{v}_{i}\right)$ as a function of wavenumber were determined by Pinnock et al. using their narrow-band radiative transfer model taking into account infrared absorption and emission by carbon dioxide, water vapor and ozone, methane, nitrous oxide and clouds, for global-average conditions, in the wavenumber range 0 to $2500 \mathrm{~cm}^{-1}$. This expression can be applied directly to experimentally determined infrared absorption cross sections. The theoretical calculations, however, provide integrated cross sections $\left(\mathrm{cm}^{2}\right.$ molecule $\left.{ }^{-1} \mathrm{~cm}^{-1}\right)$ for each vibrational mode at a precise wavenumber; however, in reality, this absorption is spread over a finite range of wavenumbers because of the rotational structure in the absorption spectra. It is found that if these vibrational modes are assumed to be Gaussian in shape, with a full width of $14 \mathrm{~cm}^{-1}$ then there is reasonable agreement between the spectral structure derived from the theory and that found in the measurements; see Figure 1 and auxiliary material. ${ }^{1}$

[15] Since the RE calculations are performed at $10 \mathrm{~cm}^{-1}$ resolution. The theoretical spectra have to be mapped on to this resolution. Three different methods were tested to achieve this: (1) the assumption that all the vibrational mode intensity is in the $10 \mathrm{~cm}^{-1}$ band in which it occurs, (2), the assumption that $50 \%$ of the absorption strength was located in the $10 \mathrm{~cm}^{-1}$ interval where the vibrational mode was determined and $25 \%$ each was located in the interval above and below this interval and (3) using the full spectrum simulated using the Gaussian functions fit described in the previous paragraph. Differences of less than 5\% between the REs calculated for the three adjustment methods were found (for instance, differences of 2 and $4.5 \%$ were found for $\mathrm{C}_{3} \mathrm{~F}_{8}$ and $n-C_{8} F_{18}$, respectively) and method 2 was chosen for the $\mathrm{RE}$ calculations presented here.

[16] There are various uncertainties that limit our ability to determine REs using radiative transfer models. These include details of the atmosphere composition, cloud amount and distribution and spectroscopic measurements. Furthermore, recent studies of $\mathrm{CF}_{3} \mathrm{CH}_{2} \mathrm{~F}$ (HFC-134a) using different radiative transfer models and a set of experimental cross sections found that even the best radiative forcing predictions only agree within 12-14\% [Gohar et al., 2004; Forster et al., 2005]. Therefore, Blowers et al. [2007] have suggested that if theoretical calculations are able to predict REs within $14-25 \%$ of existing experimental values, the calculations provide a valuable method for determining REs.

[17] The Pinnock et al. [1995] method can be tested against the multimodel comparison of Forster et al. [2005] to assess whether, despite its simplicity, it remains useful. Using the HFC-134a spectrum recommended by Forster et al. [2005], the Pinnock et al. method generates a cloudy-sky global-mean instantaneous forcing of $0.154 \mathrm{~W} \mathrm{~m}^{-2} \mathrm{ppbv}^{-1}$ compared to a forcing of $0.143-0.158 \mathrm{~W} \mathrm{~m}^{-2} \mathrm{ppbv}^{-1}$ from the more sophisticated models contributing to the comparison. The standard definition of radiative forcing usually adopted (see, e.g., Intergovernmental Panel on Climate Change (IPCC) [2007] and Pinnock et al. [1995] for more discussion) includes stratospheric temperature adjustment. Including this adjustment, which is neglected in the simple Pinnock et al. [1995] method used here, leads to a forcing ranging from 0.155 to $0.166 \mathrm{~W} \mathrm{~m}^{-2} \mathrm{ppbv}^{-1}$. This indicates that the REs derived using the Pinnock et al. method are within $10 \%$ of those derived using more detailed models.

\section{Results and Discussion}

\subsection{Infrared Absorption Cross Section}

\subsubsection{Experimental Infrared Absorption Cross Sections}

[18] Infrared spectra recorded at MSF at $297 \mathrm{~K}_{\text {for }} \mathrm{C}_{2} \mathrm{~F}_{6}$, $\mathrm{C}_{3} \mathrm{~F}_{8}, \mathrm{C}_{4} \mathrm{~F}_{10}, \mathrm{C}_{5} \mathrm{~F}_{12}, \mathrm{C}_{6} \mathrm{~F}_{14}$ and $\mathrm{C}_{8} \mathrm{~F}_{18}$ are illustrated in

\footnotetext{
${ }^{1}$ Auxiliary materials are available in the HTML. doi:10.1029/ 2010JD014771.
} 

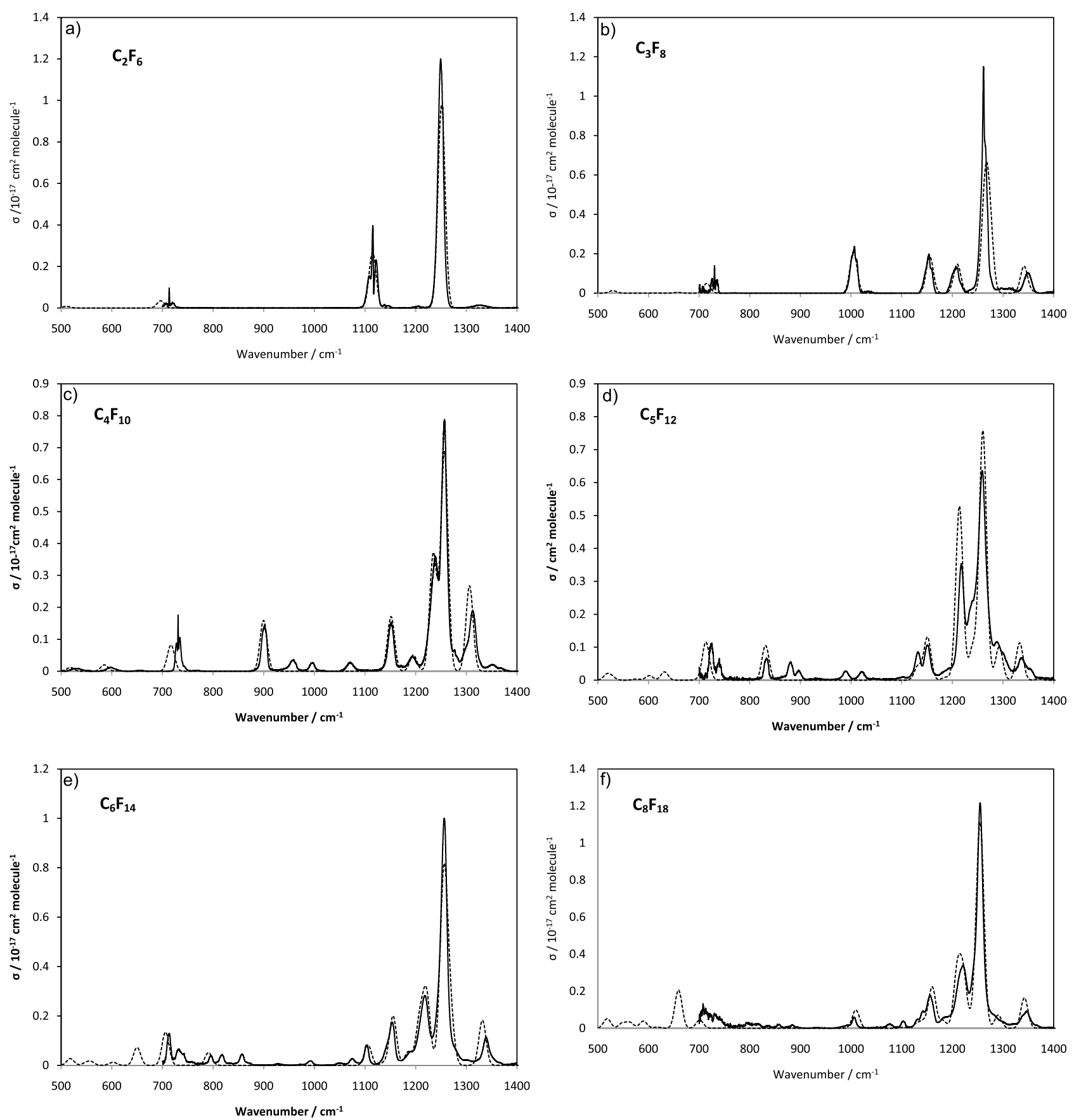

Figure 1. Measured infrared spectra of (a) $\mathrm{C}_{2} \mathrm{~F}_{6}$, (b) $\mathrm{C}_{3} \mathrm{~F}_{8}$, (c) $n-\mathrm{C}_{4} \mathrm{~F}_{10}$, (d) $n-\mathrm{C}_{5} \mathrm{~F}_{12}$, (e) $n-\mathrm{C}_{6} \mathrm{~F}_{14}$, and (f) $\mathrm{n}-\mathrm{C}_{8} \mathrm{~F}_{18}$ measured at MSF are represented by the solid curves. The spectra have been smoothed to $c a$ $1 \mathrm{~cm}^{-1}$ resolution using a sliding average method. The dashed curves represent the simulated spectra modeled using Gaussian functions of $14 \mathrm{~cm}^{-1}$ full width from the B3LYP vibrational modes. The absorption below $500 \mathrm{~cm}^{-1}$ was minor and we give the full spectra in the auxiliary material in graphical form.

Figure 1; in the case of $\mathrm{C}_{4} \mathrm{~F}_{10}, \mathrm{C}_{5} \mathrm{~F}_{12}$ and $\mathrm{C}_{6} \mathrm{~F}_{14}$ measurements were also available from Ford, which agreed well with those from MSF within experimental error. The two sets of spectra are in excellent agreement. As expected, all spectra show strong bands in the C-F stretching region between $1100-1300 \mathrm{~cm}^{-1}$. Plots of absorbance versus partial pressure of PFC showed good linearity, and zero intercepts, and no dependence on total pressure was observed. Inte- grating the spectra between 700 and $1400 \mathrm{~cm}^{-1}$ gives the integrated absorption cross sections, and these are listed in Table 1. Measurements were also made at MSF at $250 \mathrm{~K}$, but no significant differences with the integrated crosssections from the $297 \mathrm{~K}$ spectra was found, which is consistent with earlier measurements of $\mathrm{C}_{2} \mathrm{~F}_{6}$ and $\mathrm{c}-\mathrm{C}_{4} \mathrm{~F}_{8}$ over a wider temperature range reported by Ballard et al. [2000]. 
Table 1. Experimental Integrated Infrared Absorption Cross Sections for Perfluorinated n-Alkanes ${ }^{\mathrm{a}}$

\begin{tabular}{|c|c|c|c|}
\hline \multirow[b]{2}{*}{ Compound } & \multicolumn{2}{|c|}{ Integrated Cross Sections $\left(10^{-17} \mathrm{~cm}^{2}\right.$ molecule $\left.{ }^{-1} \mathrm{~cm}^{-1}\right)$} & \multirow[b]{2}{*}{ Reference } \\
\hline & S(T)/This Work, $297 \mathrm{~K}$ & $\mathrm{~S}(\mathrm{~T}) /$ Literature & \\
\hline \multirow[t]{5}{*}{$\mathrm{C}_{2} \mathrm{~F}_{6}$} & 23.1 & & This work $\left(700-1400 \mathrm{~cm}^{-1}\right) \mathrm{MSF}$ \\
\hline & & 21.7 & Sihra et al. [2001] $\left(450-2000 \mathrm{~cm}^{-1}\right)(296 \mathrm{~K})$ \\
\hline & & 22.8 & Ballard et al. [2000] $\left(675-1400 \mathrm{~cm}^{-1}\right)(293 \mathrm{~K})$ \\
\hline & & 21.6 & Roehl et al. [1995] $(500-1550)(300 \mathrm{~K})$ \\
\hline & & 26.3 & Bera et al. $[2010]^{\mathrm{a}}$ \\
\hline \multirow[t]{4}{*}{$\mathrm{C}_{3} \mathrm{~F}_{8}$} & 26.9 & & This work $\left(700-1400 \mathrm{~cm}^{-1}\right) \mathrm{MSF}$ \\
\hline & & 22.0 & Roehl et al. [1995] $\left(500-1550 \mathrm{~cm}^{-1}\right)(300 \mathrm{~K})$ \\
\hline & & 27.4 & Sihra et al. [2001] $\left(450-2000 \mathrm{~cm}^{-1}\right)(296 \mathrm{~K})$ \\
\hline & & 30.4 & Bera et al. $[2010]^{\mathrm{a}}$ \\
\hline \multirow[t]{4}{*}{$\mathrm{C}_{4} \mathrm{~F}_{10}$} & 31.6 & & This work $\left(450-1500 \mathrm{~cm}^{-1}\right)$ Ford \\
\hline & & 27.2 & Roehl et al. [1995] (500-1550 $\left.\mathrm{cm}^{-1}\right)(300 \mathrm{~K})$ \\
\hline & & 30.4 & Ko and Chang [1992] $\left(550-1425 \mathrm{~cm}^{-1}\right)(300 \mathrm{~K})$ \\
\hline & & 36.0 & Bera et al. $[2010]^{\mathrm{a}}$ \\
\hline \multirow[t]{5}{*}{$\mathrm{C}_{5} \mathrm{~F}_{12}$} & 36.5 & & This work $\left(700-1400 \mathrm{~cm}^{-1}\right) \mathrm{MSF}$ \\
\hline & 37.4 & & This work $\left(210-2000 \mathrm{~cm}^{-1}\right)$ Ford \\
\hline & & 37.1 & $\begin{array}{l}\text { C. M. Roehl et al. (personal communication, 1995) } \\
\qquad\left(675-1450 \mathrm{~cm}^{-1}\right)(300 \mathrm{~K})\end{array}$ \\
\hline & & 35.0 & Ko and Chang [1992] $\left(550-1425 \mathrm{~cm}^{-1}\right)(300 \mathrm{~K})$ \\
\hline & & 34.6 & Roehl et al. [1995] (500-1550 $\left.\mathrm{cm}^{-1}\right)(300 \mathrm{~K})$ \\
\hline \multirow[t]{5}{*}{$\mathrm{C}_{6} \mathrm{~F}_{14}$} & 38.7 & & This work $\left(700-1400 \mathrm{~cm}^{-1}\right)$ MSF \\
\hline & 39.7 & & This work $\left(210-2000 \mathrm{~cm}^{-1}\right)$ Ford \\
\hline & & 38.0 & $\begin{array}{l}\text { C. M. Roehl et al. (personal communication, 1995) } \\
\qquad\left(675-1450 \mathrm{~cm}^{-1}\right)(300 \mathrm{~K})\end{array}$ \\
\hline & & 38.1 & Ko and Chang [1992] $\left(550-1425 \mathrm{~cm}^{-1}\right)(300 \mathrm{~K})$ \\
\hline & & 39.6 & Roehl et al. [1995] $\left(500-1550 \mathrm{~cm}^{-1}\right)(300 \mathrm{~K})$ \\
\hline $\mathrm{C}_{8} \mathrm{~F}_{18}$ & 45.7 & & This work $\left(700-1400 \mathrm{~cm}^{-1}\right)$ MSF \\
\hline
\end{tabular}

${ }^{\mathrm{a}}$ Theoretical data computed at the MP2/DZP++ level of theory.

[19] Table 1 also lists integrated cross sections measured by other groups, and the range over which the integration was carried out. In general, the agreement is very good. The MSF cross section for $\mathrm{C}_{2} \mathrm{~F}_{6}$ is $6 \%$ higher than that from Ford - the former is in better agreement with the earlier measurements of Ballard et al. [2000], while the latter agrees better with Roehl et al. [1995] - in any case, the sets of measurements agree within the stated error bars. The only number that stands out from Table 1 is the integrated cross section for $\mathrm{C}_{3} \mathrm{~F}_{8}$ reported by Roehl et al. [1995] Their value is more than $20 \%$ lower than our value and that reported by Sihra et al. While the origin of this discrepancy is not clear, it may reflect the presence of air impurity in the $\mathrm{C}_{3} \mathrm{~F}_{8}$ sample employed by Roehl et al. [1995]. In the present work and the previous study by Sihra et al. [2001] the $\mathrm{C}_{3} \mathrm{~F}_{8}$ sample was frozen using liquid nitrogen and subjected to freeze-pump-thaw cycling to remove any air impurity. Roehl et al. [1995] used their sample of $\mathrm{C}_{3} \mathrm{~F}_{8}$ without such a purification procedure. It is notable that the integrated cross sections are observed to increase as the chain length increases, accepting that the results of Roehl et al. [1995] indicate only very a modest increase between $\mathrm{C}_{2}$ and $\mathrm{C}_{3}$. Our measurement of $\mathrm{C}_{8} \mathrm{~F}_{18}$ is the first to be reported.

\subsubsection{Computational Infrared Absorption Cross Section}

[20] Infrared intensities and wavenumbers of vibrational modes for $\mathrm{CF}_{4}, \mathrm{C}_{2} \mathrm{~F}_{6}, \mathrm{C}_{3} \mathrm{~F}_{8}, \mathrm{C}_{4} \mathrm{~F}_{10}, \mathrm{C}_{5} \mathrm{~F}_{12}, \mathrm{C}_{6} \mathrm{~F}_{14}$ and $\mathrm{C}_{8} \mathrm{~F}_{18}$ were obtained at MP2/6-31G** and B3LYP/6-31G** levels of theory. The wavenumbers of the main calculated vibrational modes can be related to the positions of the important experimental absorption bands and the two quantities plotted against each other, as illustrated in
Figure 2. In both cases a good correlation is found and, thus, the regression fits from these plots may be used to obtain rescaled wavenumbers. $\bar{\nu}_{\text {scal }}$, from the theoretical MP2 or B3LYP data, $\bar{\nu}_{\text {calc }}$,

$$
\bar{\nu}_{\text {scal }}=0.891 \bar{\nu}_{\text {calc }}+83.988 \mathrm{~cm}^{-1} \mathrm{r}^{2}=0.995 \mathrm{MP} 2 / 6-31 \mathrm{G}^{* *}
$$

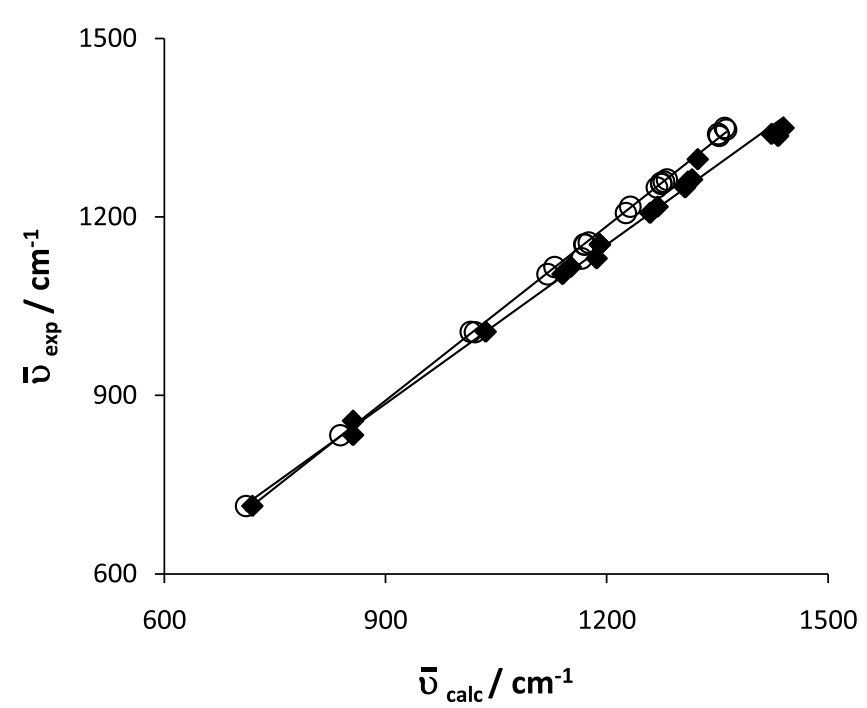

Figure 2. Plot and correlation of the frequencies of calculated vibrational modes at MP2/6-31G** (diamonds) and $\mathrm{B} 3 \mathrm{LYP} / 6-31 \mathrm{G}^{* *}$ (circles) $\left(\bar{\nu}_{\text {calc }}\right)$ versus corresponding assigned experimental frequencies $\left(\bar{\nu}_{\text {exp }}\right)$. 


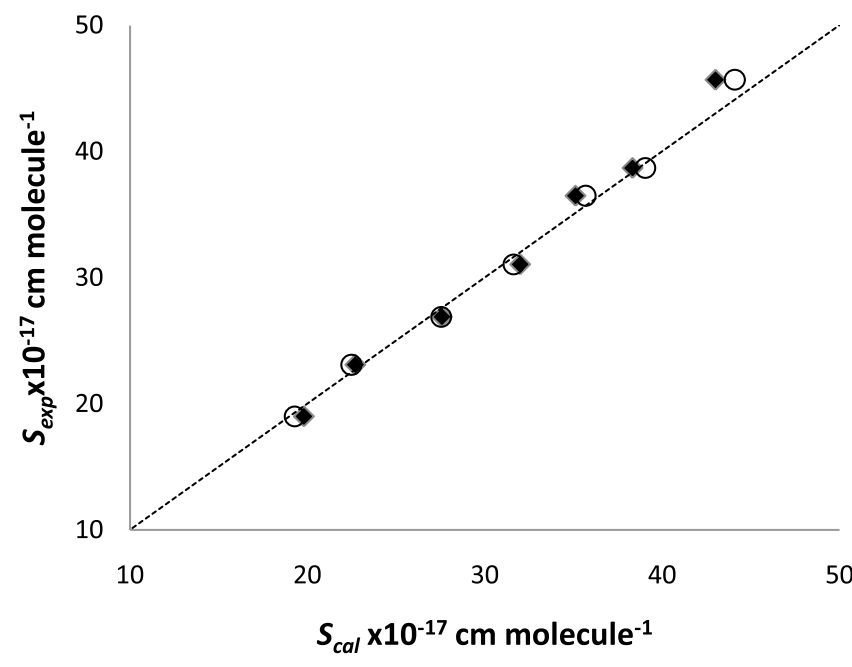

Figure 3. Plot of calculated MP2/6-31G** (diamonds) and $\mathrm{B} 3 \mathrm{LYP} / 6-31 \mathrm{G}^{* *}$ (circles) integrated cross sections versus experimental cross sections for the range of 700 $1400 \mathrm{~cm}^{-1}$. Dashed line represents the $x=y$ plot.

$\bar{\nu}_{\text {scal }}=0.977 \bar{\nu}_{\text {calc }}+11.664 \mathrm{~cm}^{-1} \mathrm{r}^{2}=0.999 \mathrm{~B} 3 \mathrm{LYP} / 6-31 \mathrm{G}^{* *}$.

[21] Other workers have used different frequency corrections. For instance, Papasavva et al. [1997] used the general frequency scale factor of 0.9427 for MP2/6-31G** calculation, suggested by Pople et al. [1993], and compared this with the simple linear relationship they found, $\bar{\nu}_{\text {scal }}=$ $0.9218 \bar{\nu}_{\text {calc }}+35 \mathrm{~cm}^{-1}$. They noted that the use of this linear relationship gave better agreement with their experimental results. Blowers et al. [2007] used a scale factor of 0.9613 obtained from Wong [1996] for their B3LYP calculations. In the present work we found an average percentage error in our peak intensity locations of 0.9 and $0.3 \%$ for MP2 and B3LYP, respectively, using relationships (1) and (2). Using the scaling factor from Pople et al. [1993] and Papasavva et al. [1997] we obtained average errors of 2.4 and $1.5 \%$ for MP2 calculations, respectively. For our B3LYP calculations, using the scaling factor from Wong [1996], we observed an average error of $2.7 \%$. The linear relationships we derive clearly give better agreement with experiment than other (less specific) frequency corrections. It is also apparent that our B3LYP relationship gives band frequencies with smaller errors than the MP2 relationship.

[22] The B3LYP DFT calculations give significantly better agreement with the experimental results. Over the range $700-1400 \mathrm{~cm}^{-1}$, the parameters of the best fit line indicate differences of less than $2 \%$ between experiment and theory of DFT calculations, but almost 5\% differences for the $\mathrm{ab}$ initio calculations.

[23] In contrast to the determination of band wavenumbers, it is difficult to assign intensities to individual bands because of overlap between bands in the experimental spectra, as reported, for example, by Papasavva et al. [1997]. We have therefore calculated the integrated cross sections of the spectra to compare theoretical and experimental spectra.

[24] Table 2 summarizes the integrated cross section calculated for the PFCs over the ranges $0-2500 \mathrm{~cm}^{-1}$ and 700 $1400 \mathrm{~cm}^{-1}$ using MP2/6-31G** and B3LYP/6-31G**, and these are compared to the experimental values, with the $\mathrm{CF}_{4}$ values taken from Hurley et al. [2005]. The agreement between the experimental integrated cross sections and the theoretical values for the integration between 700 and $1400 \mathrm{~cm}^{-1}$ is very good for both theoretical methods. The B3LYP calculations give integrated absorption cross sections that agree to better than $4 \%$, while the MP2 results agree to within $6 \%$. Extending the range of integration to $0-2500 \mathrm{~cm}^{-1}$ has only a small effect on the integrated cross sections of the smaller PFCs $(<1 \%)$, but becomes more significant for the larger compounds, particularly for $\mathrm{C}_{8} \mathrm{~F}_{18}$, where it exceeds $10 \%$. Presumably, this effect arises because of the possibility of lower-wavenumber bending vibrations in the larger compounds. As is shown in Table 1, Bera et al. [2010] reported theoretical integrated cross sections at $\mathrm{MP} 2 / \mathrm{DZP}++$ level of theory for $\mathrm{C}_{2} \mathrm{~F}_{6}, \mathrm{C}_{3} \mathrm{~F}_{8}$, and $\mathrm{C}_{4} \mathrm{~F}_{10}$, which are about $15 \%$ larger compared with the experimental and computed values presented here. Figure 3 shows the correlation between calculated and experimen-

Table 2. Integrated Infrared Cross Sections for Perfluorinated Alkanes Derived From Theoretical Calculations $\left(S_{\text {cal }}\right)$ and Experiments $\left(S_{\text {exp }}\right)$ in the Present Work $^{\mathrm{a}}$

\begin{tabular}{|c|c|c|c|c|c|}
\hline \multirow[b]{4}{*}{ Compound } & \multicolumn{5}{|c|}{ Integrated Cross Sections } \\
\hline & \multirow[b]{3}{*}{$S_{\text {exp }}(297 \mathrm{~K}) 700-1400 \mathrm{~cm}^{-1}$} & \multicolumn{4}{|c|}{$S_{c a l}($ This Work $)$} \\
\hline & & \multicolumn{2}{|c|}{$700-1400 \mathrm{~cm}^{-1}$} & \multicolumn{2}{|c|}{$0-2500 \mathrm{~cm}^{-1}$} \\
\hline & & $\mathrm{MP} 2 / 6-31 \mathrm{G}^{* *}$ & $\mathrm{~B} 3 \mathrm{LYP} / 6-31 \mathrm{G}^{* *}$ & $\mathrm{MP} 2 / 6-31 \mathrm{G}^{* *}$ & $\mathrm{~B} 3 \mathrm{LYP} / 6-31 \mathrm{G}^{* *}$ \\
\hline $\mathrm{CF}_{4}$ & $19.0 \pm 1.7^{\mathrm{b}}$ & 19.8 & 19.3 & 20.1 & 19.5 \\
\hline $\mathrm{C}_{2} \mathrm{~F}_{6}$ & $23.1 \pm 1.221 .7 \pm 1.1^{\mathrm{c}}$ & 22.7 & 22.5 & 23.0 & 22.7 \\
\hline $\mathrm{C}_{3} \mathrm{~F}_{8}$ & $26.9 \pm 1.327 .4 \pm 1.4^{\mathrm{c}}$ & 27.6 & 27.6 & 27.7 & 27.7 \\
\hline $\mathrm{C}_{4} \mathrm{~F}_{10}$ & $31.1 \pm 1.631 .1 \pm 1.6^{\mathrm{c}}$ & 32.0 & 31.6 & 32.2 & 32.5 \\
\hline $\mathrm{C}_{5} \mathrm{~F}_{12}$ & $36.5 \pm 1.835 .9 \pm 1.8^{\mathrm{d}}$ & 35.1 & 35.7 & 36.8 & 37.2 \\
\hline $\mathrm{C}_{6} \mathrm{~F}_{14}$ & $38.7 \pm 1.937 .4 \pm 1.9^{\mathrm{d}}$ & 38.3 & 39.1 & 41.2 & 41.8 \\
\hline $\mathrm{C}_{8} \mathrm{~F}_{18}$ & $45.7 \pm 2.3$ & 43.0 & 44.1 & 50.0 & 50.9 \\
\hline
\end{tabular}

${ }^{a}$ Units are $10^{-17} \mathrm{~cm}^{2}$ molecule ${ }^{-1} \mathrm{~cm}^{-1}$. All observed cross sections are from MSF measurements unless otherwise noted.

${ }^{\mathrm{b}}$ Data taken from Hurley et al. [2005] (average of MSF and Ford measurements).

${ }^{\mathrm{c}}$ Data taken from Ford, as reported by Sihra et al. [2001].

${ }^{\mathrm{d}}$ Data taken from Ford. Error bars are 5\% of accuracy. 
Table 3. Radiative Efficiencies for Perfluoroalkanes Reported Previously and Obtained in the Present Work Using Theoretical Calculations (B3LYP/6-31G** and MP2/6-31G**) and Experiments ${ }^{\mathrm{a}}$

\begin{tabular}{|c|c|c|c|}
\hline $\begin{array}{l}\text { Compound and } \\
\mathrm{RE}_{\mathrm{B} 3 \mathrm{LYP}}, \mathrm{RE}_{\mathrm{MP} 2}\left(0-2500 \mathrm{~cm}^{-1}\right)\left(700-1400 \mathrm{~cm}^{-1}\right)\end{array}$ & $\mathrm{RE}_{\text {exp }}$ & Method & References \\
\hline $\mathrm{CF}_{4}(0.08,0.09)(0.08,0.09)$ & $\begin{array}{l}0.08 \\
0.10\end{array}$ & $\begin{array}{l}\text { Pinnock } /\left(600-3700 \mathrm{~cm}^{-1}\right) \\
\text { NBM constant profile }\end{array}$ & $\begin{array}{c}\text { From the } \mathrm{CF}_{4} \text { spectrum of Hurley et al. [2005] } \\
\text { Hurley et al. }[2005]\end{array}$ \\
\hline $\mathrm{C}_{2} \mathrm{~F}_{6}(0.23,0.28)(0.23,0.27)$ & $\begin{array}{l}0.26 \\
0.22 \\
0.33 \\
0.26 \\
0.27\end{array}$ & $\begin{array}{c}\text { Pinnock/This work }\left(700-1400 \mathrm{~cm}^{-1}\right) \\
\left.\text { BBM/(500-1550 } \mathrm{cm}^{-1}\right) \\
\text { ab initio MP2/6-31G** } \\
\text { NBM constant profile } \\
\text { NBM constant profile }\end{array}$ & $\begin{array}{c}\text { Roehl et al. }[1995] \\
\text { Papasavva et al. }[1997] \\
\text { IPCC [2007]/Highwood and Shine [2000] } \\
\text { Sihra et al. }[2001]\end{array}$ \\
\hline $\mathrm{C}_{3} \mathrm{~F}_{8}(0.27,0.30)(0.27,0.29)$ & $\begin{array}{l}0.27 \\
0.23 \\
0.26 \\
0.28\end{array}$ & $\begin{array}{c}\text { Pinnock/This work }\left(700-1400 \mathrm{~cm}^{-1}\right) \\
\left.\text { BBM/(500-1550 } \mathrm{cm}^{-1}\right) \\
\text { NBM constant profile }\end{array}$ & $\begin{array}{c}\text { Roehl et al. }[1995] \\
\text { IPCC }[2007] \\
\text { Sihra et al. }[2001]\end{array}$ \\
\hline $\mathrm{C}_{4} \mathrm{~F}_{10}(0.35,0.40)(0.34,0.39)$ & $\begin{array}{l}0.34 \\
0.37 \\
0.38 \\
0.30 \\
0.33\end{array}$ & $\begin{array}{l}\text { Pinnock/This work }\left(700-1400 \mathrm{~cm}^{-1}\right) \\
\text { Pinnock/This work }\left(450-1500 \mathrm{~cm}^{-1}\right) \\
\text { NBM constant profile } \\
\left.\text { BBM/(500-1550 } \mathrm{cm}^{-1}\right)\end{array}$ & $\begin{array}{c}\text { Sihra et al. }[2001] \\
\text { Roehl et al. }[1995] \\
\quad \text { IPCC }[2007]\end{array}$ \\
\hline $\mathrm{C}_{5} \mathrm{~F}_{12}(0.40,0.42)(0.38,0.41)$ & $\begin{array}{l}0.39 \\
0.40 \\
0.41 \\
0.37\end{array}$ & $\begin{array}{l}\text { Pinnock/This work }\left(700-1400 \mathrm{~cm}^{-1}\right) \\
\text { Pinnock/This work }\left(210-2000 \mathrm{~cm}^{-1}\right) \\
\left.\text { BBM/(500-1550 } \mathrm{cm}^{-1}\right)\end{array}$ & $\begin{array}{c}\text { IPCC [2007] } \\
\text { Roehl et al. }[1995]\end{array}$ \\
\hline $\mathrm{C}_{6} \mathrm{~F}_{14}(0.42,0.48)(0.40,0.46)$ & $\begin{array}{l}0.43 \\
0.43 \\
0.49 \\
0.44\end{array}$ & $\begin{array}{l}\text { Pinnock/This work }\left(700-1400 \mathrm{~cm}^{-1}\right) \\
\text { Pinnock/This work }\left(210-2000 \mathrm{~cm}^{-1}\right) \\
\left.\text { BBM/(500-1550 } \mathrm{cm}^{-1}\right)\end{array}$ & $\begin{array}{c}\text { IPCC [2007] } \\
\text { Roehl et al. }[1995]\end{array}$ \\
\hline $\mathrm{C}_{8} \mathrm{~F}_{18}(0.50,0.55)(0.46,0.49)$ & 0.50 & Pinnock/This work $\left(700-1400 \mathrm{~cm}^{-1}\right)$ & \\
\hline
\end{tabular}

${ }^{\mathrm{a}}$ Units are $\mathrm{W} \mathrm{m}^{-2} \mathrm{ppbv}^{-1}$.

tal integrated cross sections. What is clear from Figures 2 and 3 is that the theoretical methods can give good agreement with experimental observations of band positions and intensities. Both MP2 and B3LYP methods can be used, but the performance of B3LYP is the better of the two. Combined with its much lower computational demands, this makes B3LYP the preferred method for such calculations, as has been discussed elsewhere [Halls and Schlegel, 1998].

\subsection{Radiative Efficiencies}

[25] Experimental infrared spectra were used as input into the method of Pinnock et al. [1995] to calculate REs, and the results are summarized in Table 3 where they are compared with previous calculations. In general, agreement with previous determinations is good, although the wavenumber range for the various measurements varies somewhat. However, as is clear from our theoretical calculations, which will be discussed later, this difference is expected to have only a minor effect. Our values for RE using experimentally derived spectra agree to within $10 \%$ of the average of the previously reported experimental RE values. The RE reported by Papasavva et al. [1997] using theoretically derived spectra is more than $30 \%$ greater than the average of the values derived using the experimental spectra for $\mathrm{C}_{2} \mathrm{~F}_{6}$.

[26] We now consider our REs derived using theoretically spectra. As described earlier, the agreement of the theoretical calculations of wavenumbers and intensities with experiment is very good. However, the calculation of REs for the PFCs requires very accurate wavenumbers, because the radiative forcing function of Pinnock et al. [1995] changes rapidly with wavenumber. For example, between 1200 and $1300 \mathrm{~cm}^{-1}$ - where a significant amount of the absorption for these compounds occurs - the radiative

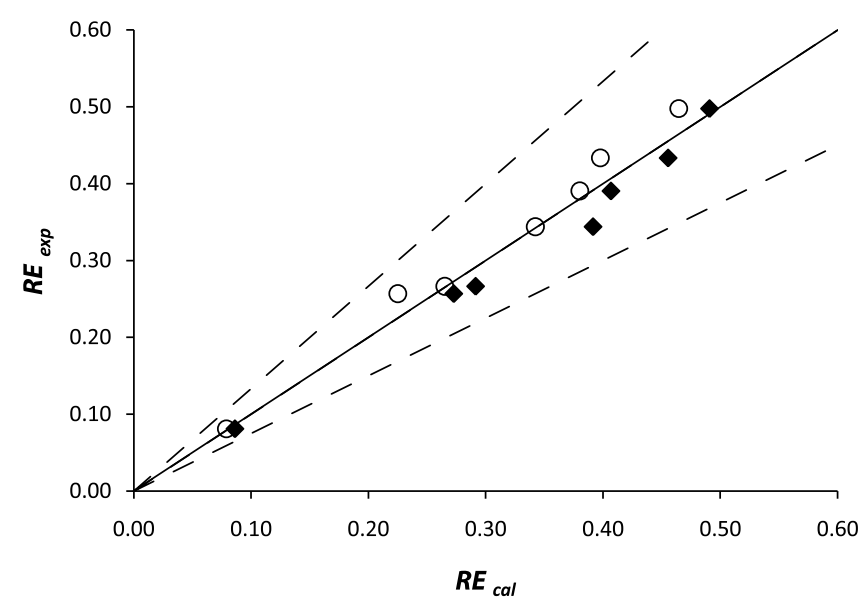

Figure 4. Radiative efficiencies predicted by the method performed here at MP2/6-31G** (diamonds) and B3LYP/ 6-31G** (circles) level of theory compared with values derived using the experimental spectra. Units are $\mathrm{W} \mathrm{m}^{-2} \mathrm{ppbv}^{-1}$. The $25 \%$ error is represented by dashed lines. 
Table 4. Global Warming Potentials, Relative to $\mathrm{CO}_{2}$, Using the Theoretical and Experimental Spectra Reported in This Work for Time Horizons of 20, 100, and 500 Years $^{\mathrm{a}}$

\begin{tabular}{|c|c|c|c|c|c|c|c|c|c|c|}
\hline \multirow[b]{2}{*}{ Compound } & \multirow[b]{2}{*}{$\tau$ (years) } & \multicolumn{3}{|c|}{$\mathrm{GWP}_{20}$} & \multicolumn{3}{|c|}{$\mathrm{GWP}_{100}$} & \multicolumn{3}{|c|}{$\mathrm{GWP}_{500}$} \\
\hline & & B3LYP & MP2 & Exp & B3LYP & MP2 & Exp & B3LYP & MP2 & Exp \\
\hline $\mathrm{CF}_{4}$ & 50,000 & 4190 & 4490 & 4250 & 5930 & 6360 & 6020 & 8970 & 9610 & 9110 \\
\hline $\mathrm{C}_{2} \mathrm{~F}_{6}$ & 10,000 & 7610 & 9150 & 8580 & 10,800 & 12,900 & 12,100 & 16,000 & 19,200 & 18,100 \\
\hline $\mathrm{C}_{3} \mathrm{~F}_{8}$ & 2600 & 6550 & 7240 & 7490 & 9160 & 10,100 & 10,500 & 12,900 & 14,200 & 14,700 \\
\hline $\mathrm{C}_{4} \mathrm{~F}_{10}$ & 2600 & 6740 & 7690 & 6570 & 9420 & 10,700 & 9180 & 13,300 & 15,100 & 12,900 \\
\hline $\mathrm{C}_{5} \mathrm{~F}_{12}$ & 4100 & 6260 & 6680 & 6160 & 8790 & 9390 & 8660 & 12,700 & 13,600 & 12,500 \\
\hline $\mathrm{C}_{6} \mathrm{~F}_{14}$ & 3200 & 5670 & 6470 & 5780 & 7940 & 9070 & 8110 & 11,300 & 13,000 & 11,600 \\
\hline $\mathrm{C}_{8} \mathrm{~F}_{18}$ & 3000 & 5230 & 5680 & 5280 & 7330 & 7950 & 7390 & 10,400 & 11,300 & 10,500 \\
\hline
\end{tabular}

${ }^{\mathrm{a}}$ Lifetimes are taken from IPCC [2007], except for $\mathrm{C}_{8} \mathrm{~F}_{18}$; see text for details.

forcing function drops by a factor of 8 . Simply using the calculated wavenumbers gives REs that are significantly lower than those determined experimentally (typically $20 \%$ for B3LYP and up to $40 \%$ for MP2). Wavenumbers were therefore corrected according to equations (1) and (2) for the MP2 and B3LYP calculations, respectively. It is these wavenumber-corrected values that reported here.

[27] In general, the REs determined from theoretical calculations $\left(\mathrm{RE}_{\mathrm{MP} 2}\right.$ and $\left.\mathrm{RE}_{\mathrm{B} 3 \mathrm{LYP}}\right)$ are in good agreement with our experimental values. However, it is notable that the $\mathrm{RE}_{\mathrm{MP} 2}$ are always larger than the $\mathrm{RE}_{\mathrm{B} 3 \mathrm{LYP}}$ values. The reason for this is that in the critical $1200-1300 \mathrm{~cm}^{-1}$ region, the scaled wavenumbers for the MP2 bands are slightly lower than those for the B3LYP bands; the bands obtained from the MP2 calculations are therefore convolved with larger values of the radiative forcing function. This point illustrates the importance of obtaining accurate wavenumbers for the position of the absorption bands. For the $\mathrm{C} 2$ to $\mathrm{C} 8$ compounds studied here, the agreement between experiment and theory is better than $10 \%$ for both methods in all cases. There is very little to choose between the two theoretical methods, but the difference in computational cost strongly favors B3LYP as the method of choice for these calculations.

[28] Plots of calculated radiative efficiencies at MP2/ 6-31G** and $\mathrm{B} 3 \mathrm{LYP} / 6-31 \mathrm{G}^{* *}$ versus experimental values are presented in Figure 4 . In Figure 4 the $25 \%$ error is represented by dashed lines; all of the computational data lie within these errors indicating that the predictions are robust.

\subsection{Global Warming Potentials}

[29] The GWP concept was introduced as a method of comparing the climate effect of emissions of different greenhouse gases [see e.g., IPCC, 2007] The GWP is usually defined relative to carbon dioxide on a mass-for-mass basis. It is the time-integrated global-mean radiative forcing of a pulse emission of $1 \mathrm{~kg}$ of some compound relative to that of $1 \mathrm{~kg}$ of the reference gas $\mathrm{CO}_{2}$, the integration being carried out over a defined time horizon.

[30] Using the experimental and computational REs reported here in section 3.2 with the absolute GWP for carbon dioxide and the PFC lifetime given by IPCC [2007] we can calculate GWPs using the standard method [see IPCC, 2007, section 2.10.1]. These values are presented in Table 4 over 20, 100 and 500 year time horizons. For $\mathrm{C}_{8} \mathrm{~F}_{18}$, no previous lifetime values are available and we used 3000 year by analogy to $\mathrm{C}_{5} \mathrm{~F}_{12}$ and $\mathrm{C}_{6} \mathrm{~F}_{16}$.

[31] The agreement between our GWP values and those of the IPCC [see, e.g., IPCC, 2007] is good, and is determined by the agreement of the RE values. So, for example, our B3LYP RE for $\mathrm{C}_{2} \mathrm{~F}_{6}$ is a little over $10 \%$ lower than the IPCC recommendation, as is the GWP value, while the MP2 $\mathrm{RE}$ for $\mathrm{C}_{5} \mathrm{~F}_{12}$ is identical to the IPCC recommendation, and the same is true for the GWP. Given that the theoretical methods developed here give good estimates of REs (better than $10 \%$ ), provided the wavenumber correction is made, they can also be used to determine GWPs with confidence.

\section{Extending the Method to Other PFCs}

[32] To extend the usefulness of our approach, we have used DFT calculations at the B3LYP/6-31G** level to determine infrared spectra for a range of linear, cyclic and branched PFCs. We apply the same empirical wavenumber correction derived for the linear PFCs (equation (2)). To test the generality of the wavenumber correction for other PFCs, we first compare integrated cross sections and REs from theoretical calculations with those using laboratory measurements for $\mathrm{c}-\mathrm{C}_{4} \mathrm{~F}_{8}, \mathrm{i}-\mathrm{C}_{4} \mathrm{~F}_{10}$, hexafluorocyclobutene, hexafluoro-1-3-butadiene, $\mathrm{c}-\mathrm{C}_{5} \mathrm{~F}_{8}$ and $\mathrm{C}_{10} \mathrm{~F}_{18}$. The experimental spectra of the latter four molecules, measured at Ford, have not previously been presented in the literature, to our knowledge, and are presented in Figure 5 (see also auxiliary material).

[33] These spectra have then been used to determine integrated cross sections and REs, and the results are in Table 5. Of the compounds examined, we are aware of only five that have been examined experimentally; $\mathrm{c}-\mathrm{C}_{4} \mathrm{~F}_{8}, \mathrm{i}-\mathrm{C}_{4} \mathrm{~F}_{10}$, hexafluoro-1-3-butadiene, $\mathrm{c}-\mathrm{C}_{5} \mathrm{~F}_{8}$ and $\mathrm{C}_{10} \mathrm{~F}_{18}$. The agreement between our predictions and the experimental results is excellent for all compounds, with both integrated cross sections and REs in agreement to within $10 \%$, and normally better. This gives us confidence to extend the method to PFCs for which no experimental spectra are available.

[34] It is also possible to determine GWPs for these compounds when atmospheric lifetimes are available. For the saturated compounds in Table 5, lifetimes on the order of thousands of years are not unreasonable, based on those of similar compounds listed in Table 4. On this basis, these compounds are expected to have GWPs on the order of 5000-15,000, dependent on RE and time horizon. For the unsaturated compounds, the lifetimes are much more difficult to calculate because such compounds will react with $\mathrm{OH}$ radicals in the troposphere, with the exact rate constants dependent on structure. For example, the rate constant for the reaction of $\mathrm{OH}$ with hexafluorobutadiene has been reported [Acerboni et al., 2001] as $1.1 \times 10^{-11} \mathrm{~cm}^{3}$ 

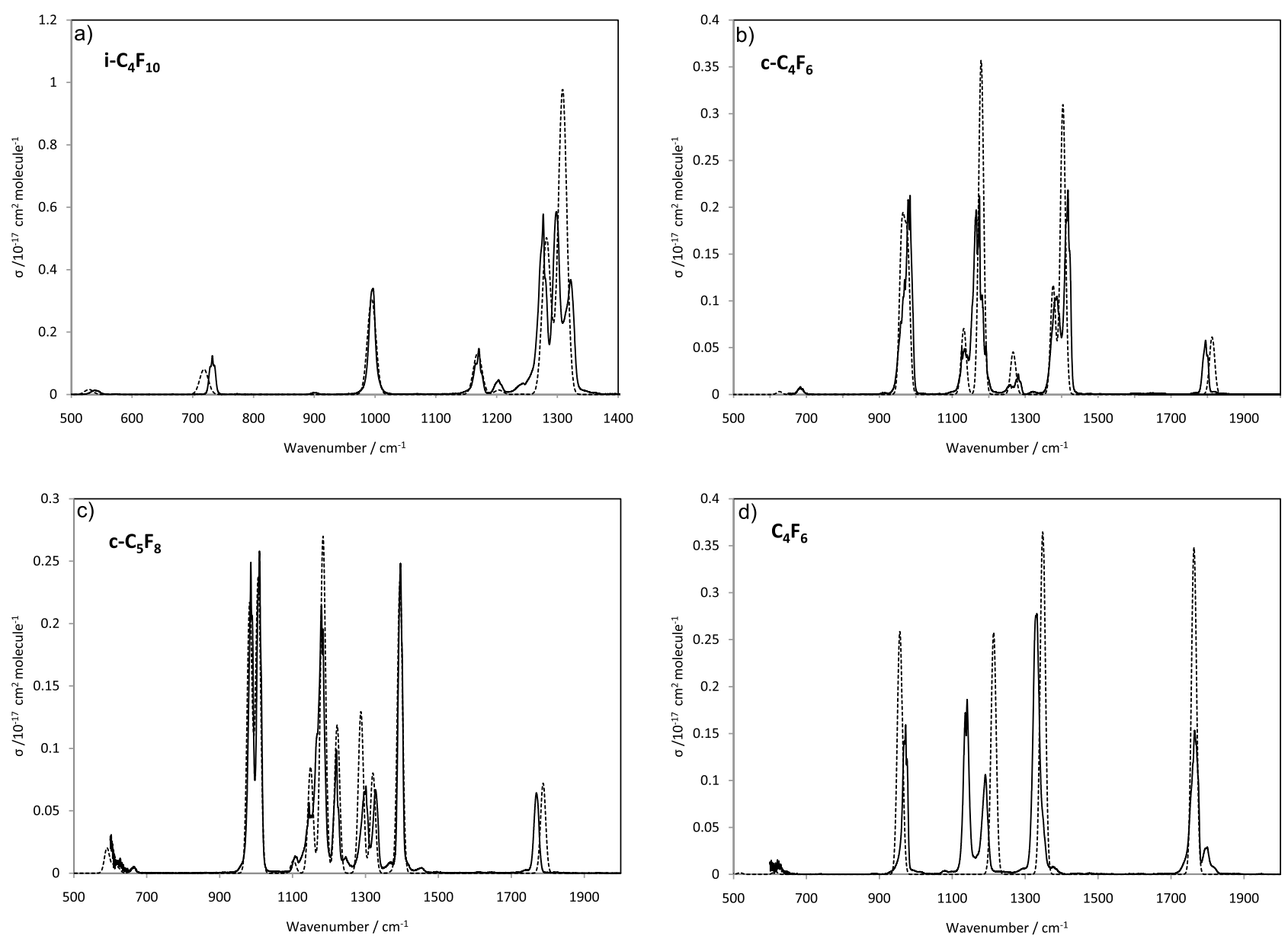

Figure 5. Measured infrared spectra of (a) $\mathrm{i}-\mathrm{C}_{4} \mathrm{~F}_{10}$ (isoperfluorobutane), (b) $\mathrm{c}-\mathrm{C}_{4} \mathrm{~F}_{6}$ (hexafluorocyclobutene), (c) $\mathrm{c}-\mathrm{C}_{5} \mathrm{~F}_{8}$ (octafluorocyclopentene), and (d) $\mathrm{C}_{4} \mathrm{~F}_{6}$ (hexafluoro-1,3-butadiene) are represented by the solid curves. The spectra have been smoothed to $\sim 1 \mathrm{~cm}^{-1}$ resolution using a sliding average method. The dashed curves represent the simulated spectra using Gaussian functions of $14 \mathrm{~cm}^{-1}$ width from the B3LYP vibrational modes. The absorption below $500 \mathrm{~cm}^{-1}$ was minor, and we give the full spectra in the auxiliary material in graphical form.

molecule $\mathrm{s}^{-1} \mathrm{~s}^{-1}$, which, assuming an $\mathrm{OH}$ concentration of $10^{6}$ molecule $\mathrm{cm}^{-3}$, gives a lifetime of 1.1 days. Using this lifetime gives GWPs of $0.85,0.24$ and 0.1 over 20, 100 and 500 year time horizons, respectively. However, as noted by Acerboni et al., such short-lived compounds do not have constant vertical profiles in the atmosphere; this means that the RE calculated using a constant vertical profile (as has been done throughout this paper; see Sihra et al. [2001] for further discussion) will be an overestimate. It is likely that the other perfluoroalkenes will have short atmospheric lifetimes and small, or negligible, GWPs.

[35] Previous studies have paid attention to how the integrated cross sections and REs increase with the number of C-F bonds in the molecule [Papasavva et al., 1997; Blowers et al., 2007; Bera et al., 2010]. Figures 6 and 7 illustrate how the integrated cross sections and REs, respectively, depend on the number of $\mathrm{C}-\mathrm{F}$ bonds. The integrated cross sections show a clear linear dependence on the number of $\mathrm{C}-\mathrm{F}$ bonds, but fall into different groups, depending on whether the compounds are linear, cyclic, or branched. For a given number of $\mathrm{C}-\mathrm{F}$ bonds, the integrated cross section increases as the number of $\mathrm{CF}_{3}$ groups in the molecule increases and decreases as the number of $\mathrm{CF}$ groups increases. This is illustrated in the series $\mathrm{c}-\mathrm{C}_{7} \mathrm{~F}_{14}$ (34.9), n- $\mathrm{C}_{6} \mathrm{~F}_{14}$ (39.1), $\left(\mathrm{CF}_{3}\right)_{2} \mathrm{CFC}_{3} \mathrm{~F}_{7}$ (45.3), $\left(\mathrm{CF}_{3}\right)_{2} \mathrm{CFCF}$ $\left(\mathrm{CF}_{3}\right)_{2}$ (47.9), $\left(\mathrm{CF}_{3}\right)_{3} \mathrm{CCF}_{2} \mathrm{CF}_{3}$ (52.1), with integrated cross sections in $\mathrm{cm}^{2}$ molecule ${ }^{-1} \mathrm{~s}^{-1}$ given in parentheses. Each of these compounds has $14 \mathrm{C}-\mathrm{F}$ bonds but integrated cross sections are seen to depend strongly on the nature of the molecular structure. The observations can be rationalized simply in a way discussed by Bera et al. [2009] For the $\mathrm{CH}_{4}, \mathrm{CH}_{3} \mathrm{~F}, \mathrm{CH}_{2} \mathrm{~F}_{2}, \mathrm{CHF}_{3}$ and $\mathrm{CF}_{4}$ series, the dipole derivatives and thus the integrated cross-sections increase due to a greater electronegativity difference between $\mathrm{C} / \mathrm{F}$ compared to $\mathrm{C} / \mathrm{H}$. For the $\mathrm{PFCs}$, each additional $\mathrm{F}$ atom renders the central $\mathrm{C}$ more positive and so greater electronegativity differences (and hence greater cross sections) are observed in the above series of compounds as the number of $\mathrm{CF}_{3}$ groups in the molecule increases.

[36] A similar effect is observed for the RE values. In this case the effect of molecular structure is almost the opposite to the observations for integrated cross sections. For example, 
Table 5. Summary of Integrated Cross Sections and Radiative Efficiencies at B3LYP/6-31G** for Some Linear, Cyclic, and Branched PFC Set and Comparison With Previous Work ${ }^{\mathrm{a}}$

\begin{tabular}{|c|c|c|c|c|}
\hline Compound & $S_{\text {B3LYP }}\left(0-2500 \mathrm{~cm}^{-1}\right)$ & $S_{\text {exp }}$ & $\mathrm{RE}_{\mathrm{B} 3 \mathrm{LYP}}\left(0-2500 \mathrm{~cm}^{-1}\right)$ & $\mathrm{RE}_{\text {exp }}$ \\
\hline \multicolumn{5}{|c|}{ Linear } \\
\hline $\mathrm{n}-\mathrm{C}_{7} \mathrm{~F}_{16}$ & 46.4 & & 0.45 & \\
\hline \multicolumn{5}{|c|}{ Cyclic } \\
\hline $\mathrm{c}-\mathrm{C}_{3} \mathrm{~F}_{6}$ & 16.9 & & 0.21 & \\
\hline $\mathrm{c}-\mathrm{C}_{4} \mathrm{~F}_{8}$ & $22.1(21.9)$ & $22.2^{\mathrm{b}}$ & 0.30 & $0.32^{\mathrm{c}}$ \\
\hline & (22.1) & $20.6^{\mathrm{d}}$ & & 0.29 \\
\hline $\mathrm{c}-\mathrm{C}_{5} \mathrm{~F}_{10}$ & 26.0 & & 0.38 & \\
\hline$c-\mathrm{C}_{6} \mathrm{~F}_{12}$ & 30.5 & & 0.46 & \\
\hline $\mathrm{c}-\mathrm{C}_{7} \mathrm{~F}_{14}$ & 34.9 & & 0.56 & \\
\hline $\mathrm{c}-\mathrm{C}_{8} \mathrm{~F}_{16}$ & 39.9 & & 0.67 & \\
\hline cis- $-\mathrm{C}_{10} \mathrm{~F}_{18}$ & 43.4 & & 0.60 & \\
\hline trans- $\mathrm{C}_{10} \mathrm{~F}_{18}$ & 43.0 & & 0.56 & \\
\hline $\mathrm{C}_{10} \mathrm{~F}_{18}{ }^{\mathrm{c}}$ & $43.2(43.2)$ & $39.1^{\mathrm{e}}$ & $0.58(0.58)$ & $0.52^{\mathrm{e}}$ \\
\hline \multicolumn{5}{|c|}{ Branched } \\
\hline $\mathrm{CF}_{3} \mathrm{CF}\left(\mathrm{CF}_{3}\right)_{2}$ & $35.8(35.8)$ & $34.4^{\mathrm{d}}$ & $0.28(0.28)$ & 0.29 \\
\hline $\mathrm{CF}_{3} \mathrm{CF}_{2} \mathrm{CF}\left(\mathrm{CF}_{3}\right)_{2}$ & 40.5 & & 0.37 & \\
\hline $\mathrm{CF}_{3} \mathrm{CF}_{2} \mathrm{CF}_{2} \mathrm{CF}\left(\mathrm{CF}_{3}\right)_{2}$ & 45.3 & & 0.41 & \\
\hline$\left(\mathrm{CF}_{3}\right)_{2} \mathrm{CFCF}\left(\mathrm{CF}_{3}\right)_{2}$ & 47.9 & & 0.40 & \\
\hline$\left(\mathrm{CF}_{3} \mathrm{CF}_{2}\right)_{2} \mathrm{CFCF}_{3}$ & 45.2 & & 0.48 & \\
\hline$\left(\mathrm{CF}_{3}\right)_{4} \mathrm{C}$ & 47.8 & & 0.31 & \\
\hline$\left(\mathrm{CF}_{3}\right)_{3} \mathrm{CCF}_{2} \mathrm{CF}_{3}$ & 52.1 & & 0.42 & \\
\hline$\left(\mathrm{CF}_{3}\right)_{2} \mathrm{CFCF}_{2} \mathrm{CF}_{2} \mathrm{CF}_{2} \mathrm{CF}_{3}$ & 50.0 & & 0.42 & \\
\hline$\left(\mathrm{CF}_{3}\right)_{2} \mathrm{CFCF}_{2} \mathrm{CF}\left(\mathrm{CF}_{3}\right)_{2}$ & 53.4 & & 0.45 & \\
\hline$\left(\mathrm{CF}_{3}\right)_{2} \mathrm{CFCF}\left(\mathrm{CF}_{3}\right) \mathrm{CF}_{2} \mathrm{CF}_{3}$ & 52.5 & & 0.48 & \\
\hline $\mathrm{CF}_{3} \mathrm{CF}_{2} \mathrm{CF}\left(\mathrm{CF}_{3}\right) \mathrm{CF}_{2} \mathrm{CF}_{2} \mathrm{CF}_{3}$ & 50.0 & & 0.52 & \\
\hline$\left(\mathrm{CF}_{3} \mathrm{CF}_{2}\right)_{3} \mathrm{CF}$ & 50.3 & & 0.57 & \\
\hline$\left(\mathrm{CF}_{3}\right)_{3} \mathrm{CCF}_{2} \mathrm{CF}_{2} \mathrm{CF}_{3}$ & 56.8 & & 0.46 & \\
\hline $\mathrm{CF}_{3} \mathrm{CF}_{2} \mathrm{C}\left(\mathrm{CF}_{3}\right)_{2} \mathrm{CF}_{2} \mathrm{CF}_{3}$ & 56.4 & & 0.49 & \\
\hline \multicolumn{5}{|c|}{ Alkenes } \\
\hline c- $\mathrm{C}_{4} \mathrm{~F}_{6}$ hexafluorocyclobutene & $23.1(22.7)$ & $21.4^{\mathrm{d}}$ & $0.30(0.29)$ & 0.28 \\
\hline $\mathrm{c}-\mathrm{C}_{5} \mathrm{~F}_{8}$ octafluorocyclopentene & $26.5(25.8)$ & $24.0^{\mathrm{d}}$ & $0.35(0.35)$ & 0.32 \\
\hline $\mathrm{CF}_{2}=\mathrm{CFCF}=\mathrm{CF}_{2}$ hexafluoro-1,3-butadiene & $21.8(21.5)$ or $21.9(21.6)$ & $20.7^{\mathrm{d}}$ & $0.21(0.21)$ & 0.20 \\
\hline
\end{tabular}

${ }^{\mathrm{a}} \mathrm{RE}$ units are $\mathrm{W} \mathrm{m}^{-2} \mathrm{ppbv}^{-1}$ and $S$ is in $10^{-17} \mathrm{~cm}^{2}$ molecule ${ }^{-1}$. Only the most stable conformers were used in the calculation. Results corresponding to the wavenumber range used in the measurements are shown in parentheses.

${ }^{\mathrm{b}}$ From Ballard et al. [2000].

${ }^{\mathrm{c}}$ From IPCC [2007]

${ }^{\mathrm{d}}$ From Ford.

${ }^{\text {e}}$ Perfluorodecalin is currently marketed as a 50:50 mixture of isomers cis and trans [Shine et al., 2005].

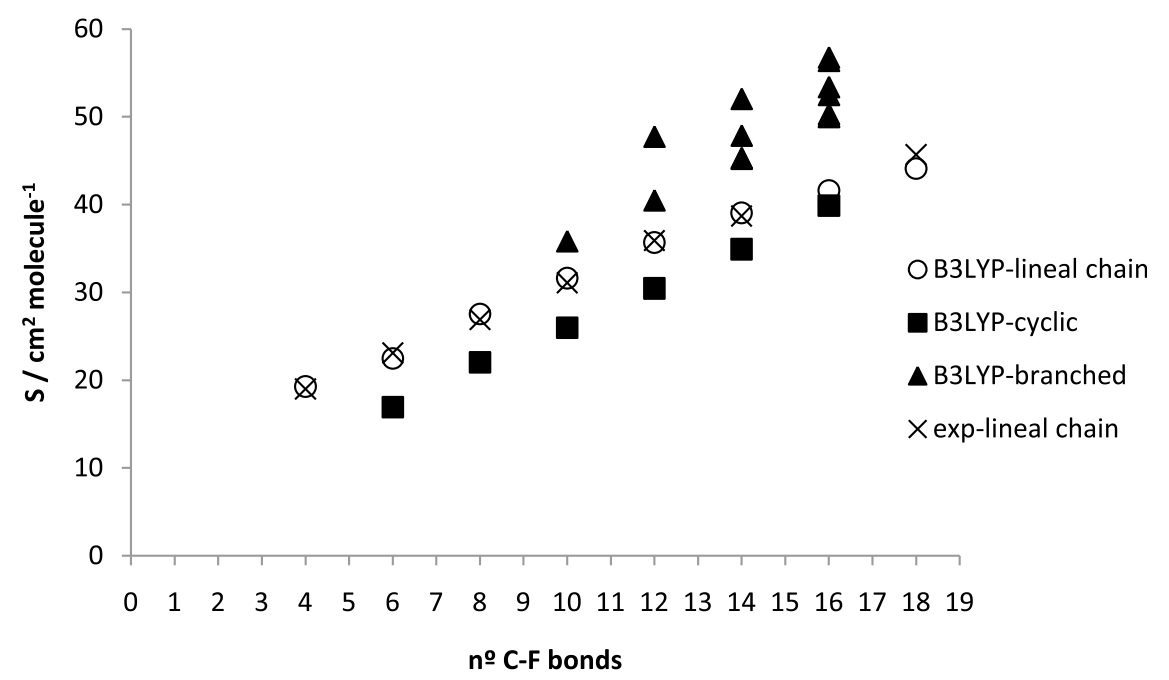

Figure 6. Plot of integrated cross sections values, S, for both computational B3LYP/6-31G** and experimental methods versus the number of $\mathrm{C}-\mathrm{F}$ bonds for the studied PFCs. Data are taken from Tables 3 and 5. 


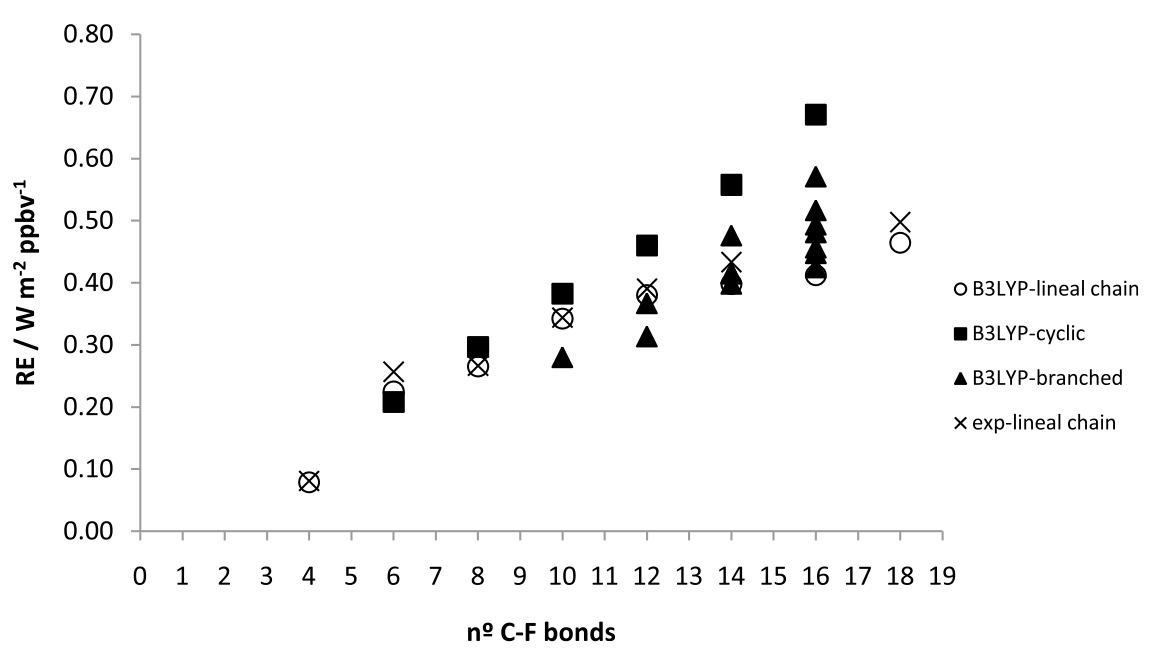

Figure 7. Plot of radiative efficiency values for both computational B3LYP/6-31G** and experimental methods versus the number of C-F bonds for the studied PFCs. Experimental data are from this work (section 3.2) except the value for $\mathrm{CF}_{4}$ (taken from Hurley et al. [2005]).

within the series considered in the previous paragraph, we find that the compound with the smallest integrated cross section $\left(\mathrm{c}-\mathrm{C}_{7} \mathrm{~F}_{14}\right)$ has the largest $\mathrm{RE}\left(0.56 \mathrm{~W} \mathrm{~m}^{-2} \mathrm{ppbv}^{-1}\right)$, while the compound with the largest integrated cross section $\left(\left(\mathrm{CF}_{3}\right)_{3} \mathrm{CCF}_{2} \mathrm{CF}_{3}\right)$ has almost the smallest $\mathrm{RE}\left(0.42 \mathrm{~W} \mathrm{~m}^{-2}\right.$ $\left.\mathrm{ppbv}^{-1}\right)$. The reason for this change in the relative magnitudes of the integrated cross sections and the RE values is that changes in structure lead to significant changes in the infrared spectra. In particular, the cyclic PFCs all have strong bands in the $1000 \mathrm{~cm}^{-1}$ region of the spectrum where the radiative forcing function is large. This was also found in the calculations of Bera et al. [2004] for cyclic perfluorocarbon radicals and anions that possessed very large integrated cross sections and where the majority of the infrared absorption falls in the atmospheric infrared window $\left(800-1200 \mathrm{~cm}^{-1}\right)$. One final comment to make about the dependence of RE on the number of C-F bonds is that for the linear PFCs, the plot is curved, with the values for the larger compounds being smaller than expected on the basis of a linear extrapolation from the smaller compounds. This nonlinear relationship arises because, while the infrared absorption increases with the length of the chain, the fraction of the absorption that lies in the atmospheric windows decreases. The same behavior was found by Bera et al. [2010] in the study of $\mathrm{CF}_{3} \mathrm{CF}_{3}$, $\mathrm{CF}_{3} \mathrm{CF}_{2} \mathrm{CF}_{3}$ and $\mathrm{CF}_{3} \mathrm{CF}_{2} \mathrm{CF}_{2} \mathrm{CF}_{3}$ and disagrees with other recent studies that show a linear dependence with the number of C-F bonds [Blowers et al., 2008a; Young et al., 2008].

[37] Young et al. [2008] provided a structure activity relationship (SAR) for the REs of HFEs we can, in principle, apply to PFCs. These authors calculated REs from the summation of the contribution of various component groups to a molecule's overall RE. For example, $-\mathrm{CF}_{3}$ adjacent to $-\mathrm{CF}_{2}$ contributes $0.162 \mathrm{~W} \mathrm{~m}^{-2} \mathrm{ppbv}^{-1},-\mathrm{CF}_{2}$ adjacent to $-\mathrm{CF}_{3}$ and $-\mathrm{CF}_{2}$ contributes $0.086 \mathrm{~W} \mathrm{~m}^{-2} \mathrm{ppbv}^{-1}$ and $-\mathrm{CF}_{2}$ adjacent to two $-\mathrm{CF}_{2}$ groups contributes $0.09 \mathrm{~W} \mathrm{~m}^{-2} \mathrm{ppbv}^{-1}$. Adopting this approach to our data, gives REs that are significantly greater than those that we have measured or estimated, particularly for the larger PFCs. For example, the approach gives an RE of $0.496 \mathrm{~W} \mathrm{~m}^{-2} \mathrm{ppbv}^{-1}$ for $\mathrm{C}_{4} \mathrm{~F}_{10}$ as opposed to our value using the experimental spectra of
$0.37 \mathrm{~W} \mathrm{~m}^{-2} \mathrm{ppbv}^{-1}$, while for $\mathrm{C}_{8} \mathrm{~F}_{18}$, the discrepancy is greater $\left(0.846\right.$ versus $\left.0.50 \mathrm{~W} \mathrm{~m}^{-2} \mathrm{ppbv}^{-1}\right)$. Given that the method was developed for a different class of compounds (HFEs rather than PFCs), it is, perhaps, not too surprising that the agreement is not particularly good. The greater discrepancy for larger molecules reflects the nonlinear dependence of RE on the number of C-F bonds illustrated in Figure 7. Interestingly, Young et al. [2008] found that their SAR tended to underpredict rather than overpredict REs for HFEs.

\section{Conclusion}

[38] Experimental quantitative infrared absorption spectra for a series of linear PFCs have been obtained and combined with the simple model of Pinnock et al. [1995] to determine radiative efficiencies and GWPs. For $\mathrm{C}_{8} \mathrm{~F}_{18}$ the data presented here are the first reported. In addition, calculations using ab initio (MP2/6-31G**) and density functional theory $\left(\mathrm{B} 3 \mathrm{LYP} / 6-31 \mathrm{G}^{* *}\right)$ methods were used to predict infrared absorption spectra. Scale factors were obtained by comparison with experimental results allowing accurate and reliable radiative efficiencies and GWPs to be determined from the theoretical calculations. We demonstrate that the theoretical calculations performed here are accurate enough to reliably predict radiative efficiencies for perfluorocarbons but only after an empirical correction to the wavenumber of absorption bands has been applied. Since MP2/6-31G** and B3LYP/6-31G** computational techniques give results with comparable accuracy, the use of $\mathrm{B} 3 \mathrm{LYP} / 6-31 \mathrm{G}^{* *}$ is recommended due to the lower computational cost. On the basis of the results for straightchain PFCs, predictions of REs for a large number of branched and cyclic PFCs were also made. For the small number of these compounds that have been examined experimentally, the agreement is excellent, indicating that our approach has more general applicability. We are currently examining the extent to which our approach can be applied to predicting REs for hydrofluoroethers (HFEs) and hydrofluoropolyethers (HFPEs). 
[39] Acknowledgments. The authors thank Gary Williams and Robert McPheat for technical support and are grateful for the computational assistance of José Rodriguez. This work was supported by the UK Engineering and Physical Sciences Research Council National Service for Computational Chemistry Software (NSCCS) and the UK Natura Environment Research Council Molecular Spectroscopy Facility. Iván Bravo also appreciates the support of the Consejería de Educación y Ciencia de la Junta de Comunidades de Castilla-La Mancha and the European Social Fund (ESF) through a postdoctoral fellowship and the Spanish Ministerio de Ciencia e Innovación (project CGL2007-62479/ CLI). Laila Gohar helped with some of the initial processing of the spectra.

\section{References}

Acerboni, G., J. A. Beukes, N. R. Jensen, J. Hjorth, G. Myhre, C. J. Nielsen, and J. K. Sunder (2001), Atmospheric degradation and global warming potentials of three perfluoroalkenes, Atmos. Environ., 35, 4113-4123, doi:10.1016/S1352-2310(01)00209-6.

Amos, R. D., N. C. Handy, W. H. Green, D. Jayatilaka, A. Willetts, and P. Palmieri (1991), Anharmonic vibrational properties of $\mathrm{CH}_{2} \mathrm{~F}_{2}$ : A comparison of theory and experiment, J. Chem. Phys., 95(11), 8323-8336, doi:10.1063/1.461259.

Ballard, J., R. J. Knight, and D. A. Newnham (2000), Infrared absorption cross-section and integrated absorption intensities of perfluoroethane and cis-perfluorocyclobutane, J. Quant. Spectrosc. Radiat. Transfer, 66, 199-212, doi:10.1016/S0022-4073(99)00217-4.

Bera, P. P., L. Horny, and H. F. Schaefer III (2004), Cyclic perfluorocarbon radicals and anions having high global warming potential (GWPs): Structures, electron affinities and vibrational frequencies, J. Am. Chem. Soc., 126, 6692-6702, doi:10.1021/ja0305297.

Bera, P. P., J. S. Francisco, and T. J. Lee (2009), Identifying the molecular origin of global warming, J. Phys. Chem. A, 113, 12,694-12,699, doi:10.1021/jp905097g.

Bera, P. P., J. S. Francisco, and T. J. Lee (2010), Design strategies to minimize the radiative efficiency of global warming molecules, Proc. Natl. Acad. Sci. U. S. A., 107, 9049-9054, doi:10.1073/pnas.0913590107.

Blowers, P., D. M. Moline, K. F. Tetrault, R. R. Wheeler, and S. L. Tuchawena (2007), Prediction of radiative forcing values for hydrofluoroethers using density functional theory methods, J. Geophys. Res., 112, D15108, doi:10.1029/2006JD008098.

Blowers, P., D. M. Moline, K. F. Tetrault, R. Wheeler, and S. L. Tuchawena (2008a), Global warming potentials of hydrofluoroethers, Environ. Sci. Technol., 42, 1301-1307, doi:10.1021/es0706201.

Blowers, P., K. F. Tetrault, and Y. Trujillo-Morehead (2008b), Global warming potential predictions for hydrofluoroethers with two carbons atoms, Theor. Chem. Acc., 119, 369-381, doi:10.1007/s00214-007-0394-3.

Bruns, R. E., P. H. Guadagnini, I. S. Scarminio, and B. de Barros Neto (1997), Multivariate statistical investigation of the effects of wave function modifications on the calculated vibrational frequencies and infrared intensities of $\mathrm{CH}_{2} \mathrm{~F}_{2}$, J. Mol. Struct., 394, 197-208.

Clerbaux, C., R. Colin, P. C. Simon, and C. Granier (1993), Infrared cross sections and global warming potentials of 10 alternative hydrofluorocarbons, J. Geophys. Res., 98, 10,491-10,497, doi:10.1029/93JD00390.

Forster, P. M. F., et al. (2005), Resolution of the uncertainties in the radiative forcing of HFC-134a, J. Quant. Spectrosc. Radiat. Transfer, 93, 447-460, doi:10.1016/j.jqsrt.2004.08.038.

Frisch, J., et al. (2004), Gaussian 03, Revision C.02, Gaussian, Inc., Wallingford, Ct.

Gohar, L. K., G. Myhre, and K. P. Shine (2004), Updated radiative forcing estimates of four halocarbons, J. Geophys. Res., 109, D01107, doi:10.1029/2003JD004320.

Halls, M. D., and H. B. Schlegel (1998), Comparison of the performance of local, gradient-corrected, and hybrid density functional models in predicting infrared intensities, J. Chem. Phys., 109(24), 10,587-10,593, doi:10.1063/1.476518.
Highwood, E. J., and K. P. Shine (2000), Radiative forcing and global warming potentials of 11 halogenated compounds, J. Quant. Spectrosc. Radiat. Transfer, 66, 169-183, doi:10.1016/S0022-4073(99)00215-0.

Hurley, M. D., T. J. Wallington, G. A. Buchanan, L. K. Gohar, G. Marston, and K. P. Shine (2005), IR spectrum and radiative forcing of $\mathrm{CF}_{4}$ revisited, J. Geophys. Res., 110, D02102, doi:10.1029/2004JD005201.

Intergovernmental Panel on Climate Change (IPCC) (2007), Fourth Assessment Report of the Intergovernmental Panel on Climate Change, edited by S. Solomon et al., Cambridge.

Ko, M. K., and D. Chang (1992), Estimates of the global warming potential of proposed chemical compounds: Report prepared for 3M Company, report, AER Inc., Cambridge, Mass.

Miller, M. D., F. Jensen, O. L. Chapman, and K. N. Houk (1989), Influence of basis sets and electron correlation on theoretically predicted infrared intensities, J. Phys. Chem., 93(11), 4495-4502, doi:10.1021/j100348a022.

Papasavva, S., S. Tai, A. Esslinger, K. H. Illinger, and J. E. Kenny (1995), $\mathrm{Ab}$-initio calculations of vibrational frequencies and infrared intensities for global warming potential of CFC substitutes $-\mathrm{CF}_{3} \mathrm{CH}_{2} \mathrm{~F}$ (HFC134a), J. Phys. Chem., 99(11), 3438-3443, doi:10.1021/j100011a006.

Papasavva, S., S. Tai, K. H. Illinger, and J. E. Kenny (1997), Infrared radiative forcing of $\mathrm{CFC}$ substitutes and their atmospheric reaction products, J. Geophys. Res., 102, 13,643-13,650, doi:10.1029/97JD01013.

Pinnock, S., M. D. Hurley, K. P. Shine, T. J. Wallington, and T. J. Smyth (1995), Radiative forcing of climate by hydrochlorofluorocarbons and hydrofluorocarbons, J. Geophys. Res., 100, 23,227-23,238, doi:10.1029/95JD02323.

Pople, J. A., A. P. Scott, M. W. Wong, and L. Radom (1993), Scaling factors for obtaining fundamental vibrational frequencies and zero-point energies from $\mathrm{HF} / 6-31 \mathrm{G}^{*}$ and $\mathrm{MP} 2 / 6-31 \mathrm{G}^{*}$ harmonic frequencies, Isr. J. Chem., 33, 345-350.

Roehl, C. M., D. Boglu, C. Bruhl, and G. K. Moortgat (1995), Infrared band intensities and global warming potentials of $\mathrm{CF}_{4}, \mathrm{C}_{2} \mathrm{~F}_{6}, \mathrm{C}_{3} \mathrm{~F}_{8}, \mathrm{C}_{4} \mathrm{~F}_{10}$, $\mathrm{C}_{5} \mathrm{~F}_{12}$, and $\mathrm{C}_{6} \mathrm{~F}_{14}$, Geophys. Res. Lett., 22, 815-818, doi:10.1029/ 95GL00488.

Shine, K. P., L. K. Gohar, M. D. Hurley, G. Marston, D. Martin, P. G. Simmonds, T. J. Wallington, and M. Watkins (2005), Perfluorodecalin: Global warming potential and first detection in the atmosphere, Atmos. Environ., 39, 1759-1763.

Sihra, K., M. D. Hurley, K. P. Shine, and T. J. Wallington (2001), Updated radiative forcing estimates of 65 halocarbons and nonmethane hydrocarbons, J. Geophys. Res., 106, 20,493-20,505, doi:10.1029/ 2000JD900716.

Wong, M. W. (1996), Vibrational frequency prediction using density functional theory, Chem. Phys. Lett., 256(4-5), 391-399.

Yamaguchi, Y., M. Frisch, J. Gaw, H. F. Schaefer III, and J. S. Binkley (1986), Analytic evaluation and basis set dependence of intensities of infrared spectra, J. Chem. Phys., 84(4), 2262-2278, doi:10.1063/ 1.450389 .

Young, C. J., M. D. Hurley, T. J. Wallington, and S. A. Mabury (2008), Molecular structure and radiative efficiency of fluorinated ethers: A structure-activity relationship, J. Geophys. Res., 113, D24301, doi:10.1029/2008JD010178.

A. Aranda and I. Bravo, Physical Chemistry Department, University of Castilla-La Mancha, Chemistry Faculty, Avda. Camilo Jose Cela 10, E-13071 Ciudad Real, Spain. (ivan.bravo@uclm.es)

M. D. Hurley and T. J. Wallington, Systems Analytics and Environmental Sciences Department, Ford Motor Company, RIC-2122, Dearborn, MI 48121-2053, USA.

G. Marston and D. R. Nutt, Department of Chemistry, University of Reading, Whiteknights POB 224, Reading RG6 6AD, UK.

K. P. Shine, Department of Meteorology, University of Reading, Earley Gate POB 243, Reading RG6 6BB, UK.

K. Smith, Space Science and Technology Department, Rutherford Appleton Laboratory, Didcot OX11 0QX, UK. 